\title{
Multilayer ceramic magnetoelectric composites with tailored interfaces for enhanced response
}

Harvey Amorín ${ }^{* \dagger}{ }^{\dagger}$ Jesús Ricote,${ }^{\dagger}$ Iván San-Felipe, ${ }^{\dagger}$ Norberto Salazar, ${ }^{\dagger,}$ Rubén del Campo, ${ }^{\dagger}$, Yonny Romaguera-Barcelay, ${ }^{\|, \perp}$ Javier Pérez de la Cruz,${ }^{\|, \#}$ Pablo Ramos, ${ }^{\nabla}$ Eladio Vila, ${ }^{\dagger}$ Alicia Castro, ${ }^{\dagger}$ and Miguel Algueró ${ }^{\dagger}$

${ }^{\dagger}$ Instituto de Ciencia de Materiales de Madrid, CSIC. Cantoblanco, 28049 Madrid, Spain

" IFIMUP and IN-Institute of Nanoscience and Nanotechnology, Faculdade de Ciências da Universidade do Porto, Rua do Campo Alegre 687, 4169-007 Porto, Portugal

${ }^{\nabla}$ Universidad de Alcalá, 28871 Alcalá de Henares, Spain

KEYWORDS: magnetoelectrics, multiferroics, ceramic composites, spark plasma sintering, piezoresponse force microscopy 
ABSTRACT: Composite materials consisting of two dissimilar ferroic phases are an excellent alternative to single-phase multiferroics for a wide range of magnetoelectric technologies. In composites with strain-mediated magnetoelectric coupling the response is strongly dependent on the characteristics of the interface between the two mechanically coupled phases. Among the different material approaches considered, cofired ceramic composites offer improved reliability in applications, and are more adequate for free-forming and miniaturization. However, their magnetoelectric response often suffers from poor reproducibility, which has been reiteratively associated with the quality of the interfaces with little experimental support. Here, we report an in-depth study of the local material properties across the interfaces of $0.36 \mathrm{BiScO}_{3}-0.64 \mathrm{PbTiO}_{3} /$ $\mathrm{NiFe}_{2} \mathrm{O}_{4}$ multilayer ceramic composites, processed by spark plasma sintering of nanocrystalline powders. Tailored microstructures and low residual stress levels were obtained by adjusting the sintering mismatch between the two ferroic phases, which also resulted in fully functional interfaces and enhanced magnetoelectric responses. 


\section{INTRODUCTION}

In magnetoelectric materials a linear electrical polarization is produced under an applied magnetic field (direct effect), and a magnetization in response to an electric one (converse effect). ${ }^{1}$ They are enabling materials for a wide range of related technologies like voltage tunable magnetic microwave components, ${ }^{2,3}$ wireless bio-implanted electronic devices, ${ }^{4}$ and high sensitivity magnetic sensors with room-temperature operation which are now the closest to their implementation in a real application. ${ }^{5,6}$

There are two main areas of research in magnetoelectric materials: single-phase multiferroics and composite materials. ${ }^{1}$ Research activity in single-phase multiferroics is extensive, and advances are being made towards obtaining room-temperature multiferroics with significant magnetoelectric effects. ${ }^{7,8}$ The perspective of having coupled ferroelectric and ferromagnetic domain configurations is also very appealing, for it allows the electrical switching of magnetization, ${ }^{9}$ and thus, it could enable a new generation of low power electrically writable, magnetically readable random access memories. ${ }^{10}$ Similarly, it makes possible the development of novel voltage controlled spintronic devices. ${ }^{11}$ However, progress is being slow as compared with that undergone with composite materials. ${ }^{12,13}$ These are basically combinations of dissimilar ferroic phases, i.e., ferroelectric and ferromagnetic components that interact either magnetically, electrostatically or elastically, as a result of which magnetoelectric coupling phenomena including linear effects and crossed switching result. ${ }^{14,15}$

The materials that are closest to applications are currently bulk magnetoelectric composites. These are combinations of piezoelectric and magnetostrictive (or piezomagnetic) components, for which magnetoelectricity is obtained as the product property of their piezoelectricity and 
effective piezomagnetism. ${ }^{16,17}$ Magnetoelectricity in these materials is strain mediated resulting in a linear magnetoelectric response. Basically the magnetostrictive component is strained under the magnetic field and the resulting strain is transmitted through the interface to the piezoelectric component, which develops an electric polarization. The interface thus plays a major role. ${ }^{18}$

The highest effective magnetoelectric coefficients have been obtained for bulk laminates combining high-permeability amorphous metal alloy ribbons and piezoelectric polymers or piezoelectric fiber structures with magnetoelectric coefficients exceeding $20 \mathrm{~V} \mathrm{~cm}^{-1} \mathrm{Oe}^{-1},{ }^{19,20}$ which have been increased up to $40 \mathrm{~V} \mathrm{~cm}^{-1} \mathrm{Oe}^{-1}$ by material selection and design. ${ }^{6,21}$ Cofired ceramic structures are also being investigated, for they offer advantages in terms of reliability and mass production, ${ }^{22,23}$ as well as being suitable for miniaturization by using techniques like ink-jet printing. ${ }^{24}$ Promising results have been obtained for layered composites of high sensitivity piezoelectric perovskite oxides, like $\mathrm{Pb}(\mathrm{Zr}, \mathrm{Ti}) \mathrm{O}_{3}$, and magnetostrictive spinel oxides. ${ }^{25,26}$ However, coefficient values are often low and poorly reproducible, which is reiteratively attributed to the quality of the interface, ${ }^{14}$ without any specific experimental study of the local material properties across it. Interfaces are thus used as a scapegoat for the unexpected low responses of magnetoelectric ceramic composites.

We report here an in-depth study of the local crystalline structure and functional material properties across the interfaces between the piezoelectric perovskite $\mathrm{BiScO}_{3}-\mathrm{PbTiO}_{3}$ and the magnetostrictive spinel $\mathrm{NiFe}_{2} \mathrm{O}_{4}$ in ceramic composites. Interest in this alternative material system has much risen, and multilayer ceramic composites with negligible interdiffusion and chemical reactions across the interfaces have recently been reported. ${ }^{27}$ In this work, results on multilayer composites processed by spark plasma sintering (SPS) from different nanocrystalline source powders are compared. This allowed densification kinetics and sintering mismatch to be 
varied, and the role of developing stresses to be qualitatively discussed. Results show how the processing can be modified to obtain tailored microstructures and low residual stress levels, which also resulted in fully functional interfaces and enhanced magnetoelectric response.

\section{EXPERIMENTAL PROCEDURE}

2.1. Composite Processing. Nanocrystalline powder of $(1-x) \mathrm{BiScO}_{3}-x \mathrm{PbTiO}_{3}$ with $x=0.64$ was obtained by mechanosynthesis in a high-energy Pulverisette 6 (Fritsch) planetary mill, as described elsewhere. ${ }^{28}$ Submicron sized agglomerates formed of highly tightened perovskite oxide nanoparticles with an average particle size of $23 \mathrm{~nm}$ resulted. They were spark plasma sintered to full densification at temperatures as low as $575^{\circ} \mathrm{C} .{ }^{29}$

Two different sources of $\mathrm{NiFe}_{2} \mathrm{O}_{4}$ nanocrystalline powders were tested. These were spinel oxide nanoparticles obtained by either mechanochemical activation or wet chemistry routes, followed by a thermal treatment at $600{ }^{\circ} \mathrm{C}$ in both cases. Details of the two synthesis routes can be found elsewhere, ${ }^{27,28}$ and average particle sizes of 30 and $35 \mathrm{~nm}$ resulted from the calcination, respectively. Though starting particle size is very similar, and full densification could be achieved with both source powders (for sintering above $800^{\circ} \mathrm{C}$ ), the SPS behavior was not equivalent in each case, as it will be shown later.

$0.36 \mathrm{BiScO}_{3}-0.64 \mathrm{PbTiO}_{3}(\mathrm{BSPT})$ and $\mathrm{NiFe}_{2} \mathrm{O}_{4}$ tapes were prepared separately by tape casting of ethanol-based formulations, and then alternately stacked and laminated. Composites of green ceramic layers were thermally treated at $500{ }^{\circ} \mathrm{C}$ to burn the organics. Then, they were spark plasma sintered at temperatures between 800 and $1000{ }^{\circ} \mathrm{C}$ under $100 \mathrm{MPa}$, with an average heating rate of $180{ }^{\circ} \mathrm{C} \min ^{-1}$ and a total processing time of $10 \mathrm{~min}$ (Dr. Sinter 2080 Sumimoto apparatus), as detailed elsewhere. ${ }^{27}$ High-quality, dense multilayer ceramic composites could be 
achieved in all cases. The highest magnetoelectric responses were achieved for multilayers processed at $900{ }^{\circ} \mathrm{C}$ from both $\mathrm{NiFe}_{2} \mathrm{O}_{4}$ source powders. This is due to a trade-off between grain growth of the piezoelectric component and microstructural degradation of the magnetostrictive one. ${ }^{27}$ Increasing the sintering temperature results in an enhancement of the piezoelectric coefficients as the grain size goes from the nano- to the micro-scale, but degradation of the $\mathrm{NiFe}_{2} \mathrm{O}_{4}$ microstructure is triggered at $1000{ }^{\circ} \mathrm{C}$. Therefore, results here shown are those for composites processed at $900{ }^{\circ} \mathrm{C}$, for which a final densification about $99 \%$ was achieved.

2.2 Composite Characterization. Ceramic microstructures across the multilayer structures were characterized by field-emission scanning electron microscopy with a FEI Nova NanoSEM 230 apparatus on cross section specimens cut perpendicular to the stacking plane. Samples were prepared by polishing with $\mathrm{Al}_{2} \mathrm{O}_{3}$ suspensions down to $0.1 \mu \mathrm{m}$. Same type of cross-section specimens were used for local crystalline structure and functional characterizations after annealing at $650{ }^{\circ} \mathrm{C}$ for $2 \mathrm{~h}$ with $\pm 1{ }^{\circ} \mathrm{C} \min ^{-1}$ heating / cooling rates. This was carried out to remove polishing effects on domain configurations.

Local crystalline structure across interfaces was studied by micro-Raman. This is a nondestructive optical spectroscopic technique that probes lattice dynamics and provides information about phases, phase transitions and strain states with high-spatial resolution. ${ }^{30}$ Raman spectra were recorded using a Jobin-Yvon LabRaman spectrometer. A HeNe laser of $632.8 \mathrm{~nm}$ wavelength was used giving a monochromatic red light at a working power of $20 \mathrm{~mW}$. The laser beam spot had a diameter of $\sim 1 \mu \mathrm{m}$ on the sample surface. Raman studies were carried out in the $100-1000 \mathrm{~cm}^{-1}$ frequency range, with the specimens placed in a micro-Raman set-up. ${ }^{31}$ 
The local piezoelectric behavior was studied by piezoresponse force microscopy (PFM), ${ }^{32}$ using a commercial scanning force microscope $\left(\text { Nanotec }{ }^{\circledR} \text { with } \text { WSxM }^{\circledR} \text { software }\right)^{33}$ and conductive Pt/Ir coated tips on cantilevers with a force constant of $42 \mathrm{~N} \mathrm{~m}^{-1}$ (NanoSensors). An external $\mathrm{AC}$ voltage with amplitudes up to $1.5 \mathrm{~V}$ and frequency of $50 \mathrm{kHz}$ was applied between the tip and the sample, while the deflection and torsion signals from the cantilever were detected by lock-in amplifiers, in order to obtain the out-of-plane and the in-plane piezoelectric responses. Local in-field (measurements with the DC bias applied) piezoelectric hysteresis loops were measured at different locations. In this work, we will consider $z$ the direction normal to the sample surface. In the plane of the sample, $\mathrm{x}$ will be the direction perpendicular to the cantilever, and $y$ the direction parallel to it.

The study of potential changes of the ferroelectric domain configuration and piezoelectric activity of the $0.36 \mathrm{BiScO}_{3}-0.64 \mathrm{PbTiO}_{3}$ next to the interface with $\mathrm{NiFe}_{2} \mathrm{O}_{4}$ was carried out by quantitative analysis of the piezoresponse along profiles perpendicular to the interface. An example of the measurements and brief description of the analysis can be found in Figure S1 of the Supporting Information. From this analysis an ensemble of experimental data of the size, number of domains and piezoelectric coefficient of grains at set distances from the interface is obtained. To be statistically reliable, 75-100 grains were measured at each interface (from 5-6 profiles in 3-4 different PFM images). A comparison between the piezoresponse of the regions closest to the interface and the rest of the piezoelectric layer is carried out. 


\section{RESULTS AND DISCUSSION}

3.1. Interface tailoring through processing. The basic characteristics of the SPS procedure followed in this work are shown in Figure 1a, along with the densification curves of the ceramics obtained from the individual powders in control experiments (Figure 1b) and that for a multilayer composite (Figure 1c). Experimentally, temperature increased up to $650{ }^{\circ} \mathrm{C}$ in $60 \mathrm{~s}$, from which the target value of $900{ }^{\circ} \mathrm{C}$ was reached in other additional $250 \mathrm{~s}$. Loading started after $60 \mathrm{~s}$ and the target pressure of $100 \mathrm{MPa}$ was reached about $140 \mathrm{~s}$ later. High temperature and pressure conditions were then maintained for an additional $300 \mathrm{~s}$.

Full densification of $0.36 \mathrm{BiScO}_{3}-0.64 \mathrm{PbTiO}_{3}$ takes place basically in two steps (see dashed lines separating them in Figure 1b): (i) a very fast shrinkage that achieves $80 \%$ in only $15 \mathrm{~s}$ after initial heating and loading (at $\sim 725^{\circ} \mathrm{C}$ and $35 \mathrm{MPa}$ ), and (ii) a slower shrinkage up to complete material densification at the same time that full loading is reached. This occurs at a temperature of $800{ }^{\circ} \mathrm{C}$. No further changes in shrinkage were found until the target temperature of $900{ }^{\circ} \mathrm{C}$ is reached and maintained during several minutes. It is obvious that grain growth processes must continue during this time, but the densification of the sample is not affected.

Densification curves for the $\mathrm{NiFe}_{2} \mathrm{O}_{4}$ powders are shown in Figure 1b. Densification kinetics is clearly slower for $\mathrm{NiFe}_{2} \mathrm{O}_{4}$ than for $0.36 \mathrm{BiScO}_{3}-0.64 \mathrm{PbTiO}_{3}$, and also the $\mathrm{NiFe}_{2} \mathrm{O}_{4}$ powder prepared by mechanochemical activation (NFO-MA) showed slower kinetics than the one obtained by wet-chemistry route (NFO-WC). Contrary to the case of $0.36 \mathrm{BiScO}_{3}-0.64 \mathrm{PbTiO}_{3}$, densification occurred in three stages for the magnetostrictive material: (i) densification after stage 1 was only of 40 and $35 \%$ for the NFO-WC and NFO-MA powders respectively, as compared with $80 \%$ for the piezoelectric material, (ii) further shrinkages up to 95 and $75 \%$ were 
achieved after stage 2 (under full loading) for the NFO-WC and NFO-MA powders respectively, and (iii) complete material densification obtained after $\sim 240 \mathrm{~s}$ for the NFO-WC powder (that is, under full loading and at a temperature of $830{ }^{\circ} \mathrm{C}$ ), and after $\sim 360 \mathrm{~s}$ for the NFO-MA powder (already at the target temperature of $900{ }^{\circ} \mathrm{C}$ ). As for $0.36 \mathrm{BiScO}_{3}-0.64 \mathrm{PbTiO}_{3}$, final densifications above $99 \%$ (relative to the theoretical ones) were achieved in these two cases.

The difference in densification kinetics must cause the sintering of the composites to take place under developing in-plane stress fields: tensile within the piezoelectric component and compressive within the magnetostrictive one. Indeed, the SPS shrinkage curves for the multilayer composites indicate intermediate kinetics between those of $0.36 \mathrm{BiScO}_{3}-0.64 \mathrm{PbTiO}_{3}$ and $\mathrm{NiFe}_{2} \mathrm{O}_{4}$ components, as it is illustrated in Figure 1c for a multilayer prepared with NFO-MA powder. This means that densification of $0.36 \mathrm{BiScO}_{3}-0.64 \mathrm{PbTiO}_{3}$ is hindered while that of $\mathrm{NiFe}_{2} \mathrm{O}_{4}$ is fostered in the composite during cosintering process. This is a case study of constrained, and specifically of differential sintering. ${ }^{34}$ Although the development of cracks has been reported as a result of the sintering mismatch, ${ }^{35}$ in the current case high-quality composites were obtained. This is true even for the most unfavorable case; that is, multilayers processed from the magnetic spinel oxide obtained by mechanochemical activation, as illustrated in the cross-section image inserted in Figure 1c, in which no cracks are visible across the interfaces. 
a)

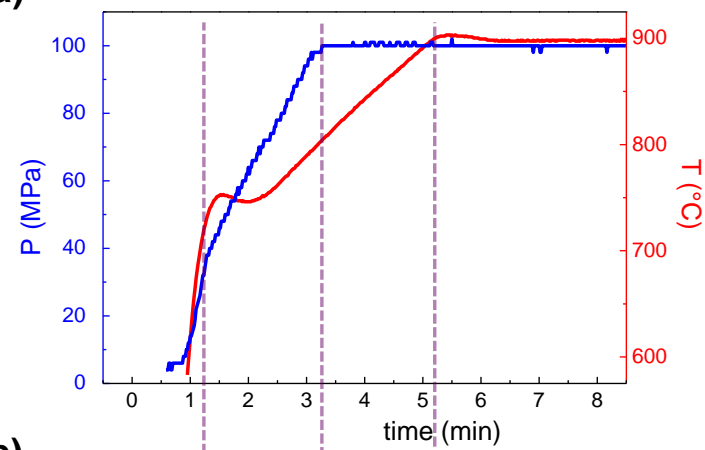

b)

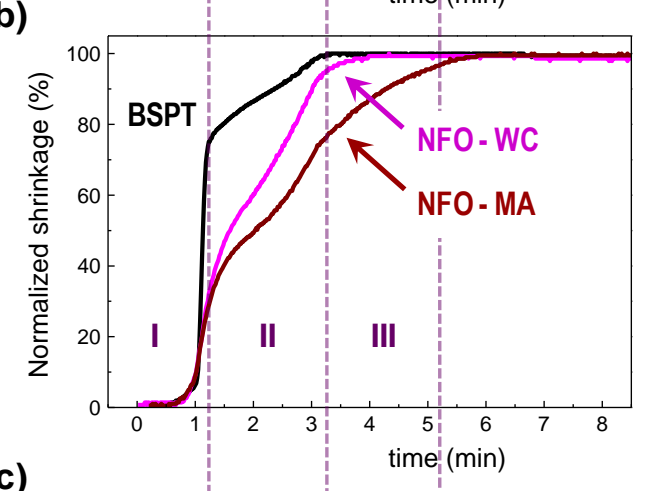

c)

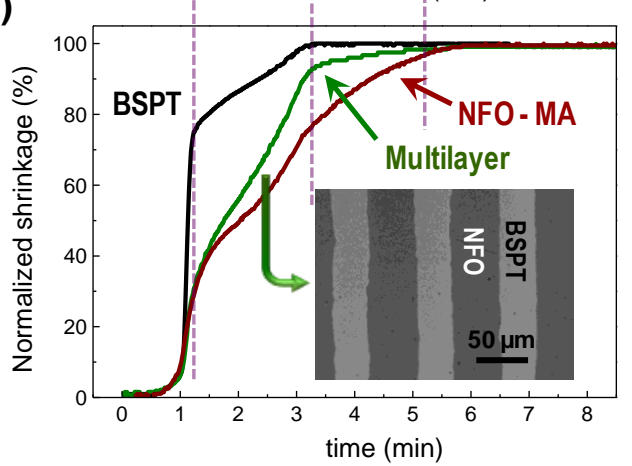

d)

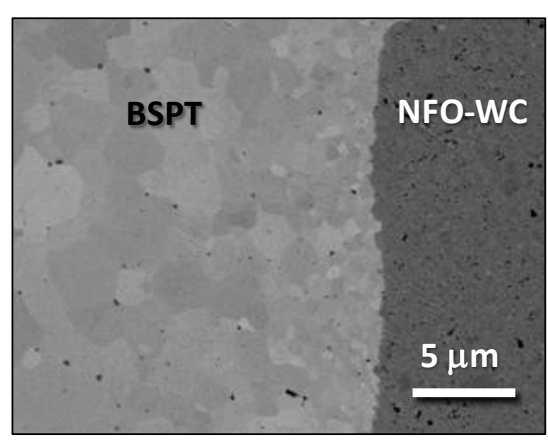

e)

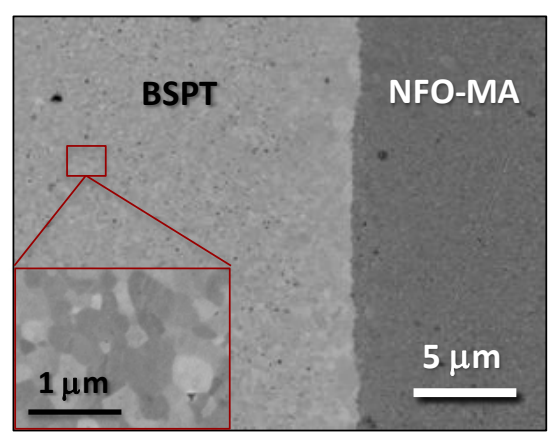

f)

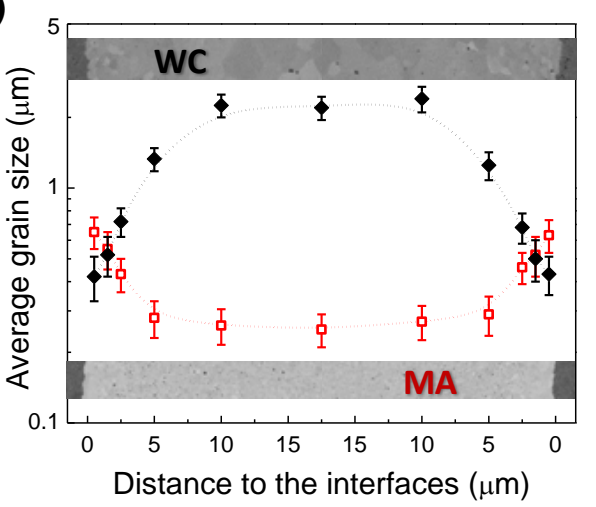

Figure 1. (a) Thermal (in red) and Pressure (in blue) profiles used in the SPS processing, dashed lines indicate different sintering stages. Normalized shrinkage curves recorded during the SPS of (b) individual $0.36 \mathrm{BiScO}_{3}-0.64 \mathrm{PbTiO}_{3}$ and $\mathrm{NiFe}_{2} \mathrm{O}_{4}$ powders (the latter for both NFO-MA and NFO-WC), and (c) a multilayer composite prepared with NFO-MA powder (a cross-section image illustrates the high quality of the interfaces). SEM images across the interface of multilayer composites prepared from different source $\mathrm{NiFe}_{2} \mathrm{O}_{4}$ powders, (d) by wet chemistry and (e) by mechanochemical activation. (f) Average grain size across the piezoelectric layer from one interface to the other in both multilayers. 


\subsection{Microstructures and residual stresses across the piezoelectric layers. Ceramic}

microstructures at the interfaces for multilayers prepared from the two different source $\mathrm{NiFe}_{2} \mathrm{O}_{4}$ powders are shown in Figure 1d,e. Neither secondary phases nor compositional gradients that might indicate chemical reactions at or interdiffusion across the interface are observed. They are effectively minimized by the short total processing time enabled by the combination of SPS and the highly-reactive nanocrystalline powders obtained by either mechanochemical activation or wet chemistry. It must be noted that $\mathrm{Pb}$ diffusion from the $0.36 \mathrm{BiScO}_{3}-0.64 \mathrm{PbTiO}_{3}$ into the $\mathrm{NiFe}_{2} \mathrm{O}_{4}$ component, and its reaction with traces of tungsten resulting from the mechanical activation of $\mathrm{NiO}$ and $\mathrm{Fe}_{2} \mathrm{O}_{3}$ in WC milling media, has been reported when hot-pressing sintering is used. ${ }^{28}$ However, these phenomena seem to be minimized in the SPS samples.

A major feature is the presence of distinct microstructural gradients across the piezoelectric component for both multilayered materials, yet of different character. Indeed, a much finer microstructure of the $0.36 \mathrm{BiScO}_{3}-0.64 \mathrm{PbTiO}_{3}$ ceramic layer was found in the case of the multilayer with NFO-MA than that of the multilayer with NFO-WC, as shown in the inset image in Figure 1e. It should be noted that microstructural gradients were not found across the magnetic layers, despite the different source of magnetic powder used. Moreover, a similar average grain size of $\sim 0.3 \mu \mathrm{m}$ resulted in both NFO-MA and NFO-WC components.

In the multilayer with NFO-MA, piezoelectric layers with typical thickness $\sim 35 \mu \mathrm{m}$ showed average grain sizes below $0.3 \mu \mathrm{m}$ all across the entire layers, yet slightly coarsened right next to the interfaces with average grain size of $\sim 0.6 \mu \mathrm{m}$, as shown in Figure 1f. On the contrary, the average grain size of the piezoelectric layers for the multilayer with NFO-WC was consistently beyond the micron, similarly to that of analogously processed $0.36 \mathrm{BiScO}_{3}-0.64 \mathrm{PbTiO}_{3}$ ceramics. 
Besides, opposite gradients were found, i.e., thin layers (thickness of about $3 \mu \mathrm{m}$ ) of submicron sized grains (from 0.4 to $0.7 \mu \mathrm{m}$ ) next to the interfaces, that readily coarsened with the distance to it (see Figure 1f). These microstructural gradients in the piezoelectric layers of both multilayers are consistent with previous results on three-layer structures. ${ }^{27}$

The distinct microstructural gradients across the piezoelectric component can be attributed to the differential sintering followed by the two components of the composite. It should be noted that $0.36 \mathrm{BiScO}_{3}-0.64 \mathrm{PbTiO}_{3}$ densification is expected to be hindered, due to the densification mismatch with $\mathrm{NiFe}_{2} \mathrm{O}_{4}$ in the multilayers during sintering. This is the largest for the multilayer with NFO-MA (Figure 1b), and as a consequence a finer microstructure of the piezoelectric component was obtained. It is also noticeable the occurrence of microstructural gradients, with smaller grain sizes next to the interface, in the composite processed with NFO-WC powder. This can be attributed to the stress accumulated at the interfaces during cosintering, which relaxes with the distance to it. The stressed region in the piezoelectric component of the multilayer with NFO-WC would then extend for $\sim 3 \mu \mathrm{m}$ from the interface, as it can be seen in the image of Figure 1d. On the other hand, the very fine grained microstructure in the multilayer with NFOMA (Figure 1e) seems to indicate limited stress relaxation in this case, and thus, the presence of a non-negligible residual tensile stress within the piezoelectric layer.

Micro-Raman studies across the interfaces confirm the scenario in which stresses accumulated within the piezoelectric layers during cosintering. Raman spectra at different positions across the interface are shown in Figure 2a,b for layered composites prepared with NFO-WC and NFOMA. To ensure that full stress relaxation is achieved within the piezoelectric component, threelayer structures with $1 \mathrm{~mm}$ thickness per layer rather than multilayers were used in these 
experiments. No additional bands other than those of the $0.36 \mathrm{BiScO}_{3}-0.64 \mathrm{PbTiO}_{3}$ and $\mathrm{NiFe}_{2} \mathrm{O}_{4}$ components were found in any of the two cases, which confirm the absence of secondary phases. The $\mathrm{PbWO}_{4}$ phase reported at interfaces of hot-pressed layered BSPT/NFO-MA composites, ${ }^{28}$ as a result of interdiffusion and chemical reactions, is not present, thus indicating these phenomena to be effectively minimized by the SPS processing.

Coexisting bands of the two components were only found when measurements are carried out on the interface or at one spot away from it (labeled Limit in Figure 2a,b). This is most probably associated with a certain inclination of the plane of the interface, which may be not perfectly perpendicular to the sample surface on which measurements are taken, and thus components on both sides of the interface contribute to the measurement. Otherwise, the typical spectra of the isolated phases were obtained at positions far away from the interface. The spectra taken at 200 $\mu \mathrm{m}$ from the interface, within the piezoelectric component, for both composites are compared with the typical spectrum obtained for a $0.36 \mathrm{BiScO}_{3}-0.64 \mathrm{PbTiO}_{3}$ coarse grained ceramic in Figure 2c. No differences are observed. Previous band assignment according to the Raman mode classification for tetragonal $\mathrm{P}_{4} \mathrm{~mm} \mathrm{PbTiO}_{3}$ is also included (solid colored lines), together with two bands assigned to the coexisting monoclinic $\mathrm{Cm}$ phase at 700 and $825 \mathrm{~cm}^{-1}$ (dashed lines). ${ }^{36}$ $0.36 \mathrm{BiScO}_{3}-0.64 \mathrm{PbTiO}_{3}$ composition under study is located at the morphotropic phase boundary (MPB), where coexistence of phases occurs, for enhanced piezoelectric response. ${ }^{37}$ 

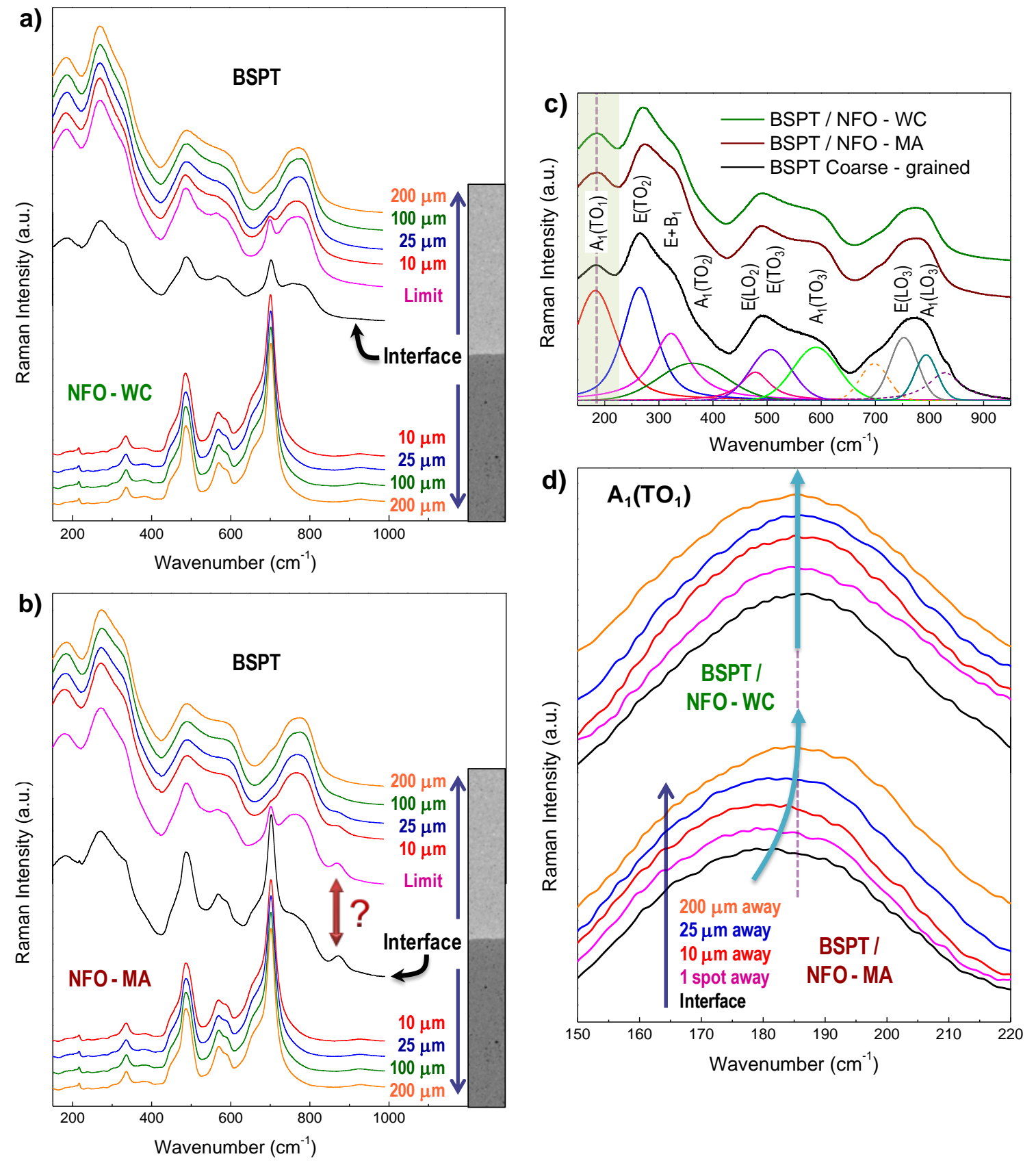

Figure 2. Micro-Raman spectra at different positions across the interfaces of three-layer composites, with $\mathrm{NiFe}_{2} \mathrm{O}_{4}$ prepared by (a) wet chemistry and (b) mechanochemical activation. Limit spectrum corresponds to one spot $(\sim 1 \mu \mathrm{m})$ from the interface. (c) Raman spectra for a coarse grained $0.36 \mathrm{BiScO}_{3}-0.64 \mathrm{PbTiO}_{3}$ ceramic, and for BSPT/NFO-WC and BSPT/NFO-MA three-layer composites at $200 \mu \mathrm{m}$ from the interface within the piezoelectric component. Modes 
assigned according to classification for tetragonal $\mathrm{PbTiO}_{3}$ (solid colored lines) and coexisting monoclinic phase (dashed lines). (d) Position of the $\mathrm{A}_{1}\left(\mathrm{TO}_{1}\right)$ soft mode versus distance from the interface within the $0.36 \mathrm{BiScO}_{3}-0.64 \mathrm{PbTiO}_{3}$ for both composites.

Note the presence of an extra mode at $875 \mathrm{~cm}^{-1}$ in the $0.36 \mathrm{BiScO}_{3}-0.64 \mathrm{PbTiO}_{3}$ close to the interface with the $\mathrm{NiFe}_{2} \mathrm{O}_{4}$ prepared by mechanochemical activation (labeled as ? in Figure 2b), which is not present in the piezoelectric material close to the $\mathrm{NiFe}_{2} \mathrm{O}_{4}$ prepared by wet chemistry (Figure 2a). This peak also appears in nanostructured $0.36 \mathrm{BiScO}_{3}-0.64 \mathrm{PbTiO}_{3}$ materials (see Figure S2 of the Supporting Information), and thus, seems to be a consequence of the reduced grain size rather than to any interface chemical reaction. Size driven perovskite polymorphic phase transitions have been described in MPB compositions of $\mathrm{Pb}\left(\mathrm{Mg}_{1 / 3} \mathrm{Nb}_{2 / 3}\right) \mathrm{O}_{3}-\mathrm{PbTiO}_{3}{ }^{38}$

The band at $\sim 189 \mathrm{~cm}^{-1}$ has been assigned to the $\mathrm{A}_{1}\left(\mathrm{TO}_{1}\right)$ mode, ${ }^{36}$ which is the ferroelectric soft phonon mode. This mode appears at the ferroelectric transition, and it hardens, that is, it shifts towards high wavenumbers on cooling. The opposite effect has been described under stress fields in ferroelectric films. ${ }^{39}$ Indeed, the $\mathrm{A}_{1}\left(\mathrm{TO}_{1}\right)$ position in the three-layer structure is shifted to lower wavenumbers as we approach the interface with the NFO-MA, unlike to that prepared with the NFO-WC where the position is the same at any distance from interface, as shown in Figure 2d. Moreover, this position relaxes in the former towards the usual $\sim 189 \mathrm{~cm}^{-1}$ with increasing distance from interface, reaching similar values in both composites at $200 \mu \mathrm{m}$. This indicates that a stress field is clearly present at the interface of the composite when NFO-MA is used, and that it is not entirely relaxed at distances of $25 \mu \mathrm{m}$ within the $0.36 \mathrm{BiScO}_{3}-0.64 \mathrm{PbTiO}_{3}$. This must be taken into account when BSPT/NFO-MA multilayers with a layer thickness of about $35 \mu \mathrm{m}$ are studied, as unrelaxed stresses most probably exist across the whole piezoelectric 
layers. On the contrary, it also indicates that significant stresses are not present in the case of the composites processed from NFO-WC, but perhaps for a very thin layer next to the interface, beyond the spatial resolution of Raman. It must be pointed out that the band has been proposed to actually be the combination of the soft mode and of the $\mathrm{A}_{1}\left(\mathrm{LO}_{1}\right)$ and $\mathrm{E}\left(\mathrm{LO}_{1}\right)$ ones, shifted and convoluted into a single band due to strains developed upon the simultaneous perovskite $A$ - and $B$-site substitution. ${ }^{36}$ Nonetheless, this does not invalidate the previous discussion.

This micro-Raman study in combination with the microstructure characterization confirms the role of the sintering mismatch and associated stresses in the evolution of ceramic microstructure. However, contrary to the case of the multilayer with NFO-WC, the evolving stress fields present during sintering close to the interfaces cannot explain the opposite microstructural gradient developed within the piezoelectric layer when NFO-MA powder is used. The layer of coarsened grains at the interfaces in this case might indicate the occurrence of exaggerated grain growth, as that already described for hot-press sintered composites using NFO-MA powder. ${ }^{28}$ In the latter case, it was attributed to the mentioned $\mathrm{Pb}$ diffusion into the magnetic oxide, which resulted in a layer of largely coarsened, piezoelectrically inactive grains. A compositional deviation towards $\mathrm{BiScO}_{3}$ was then proposed. It is thus sensible to assume that the same phenomena, yet at a much less extent, could also take place during the SPS experiment. So the question is how the distinct interface-induced microstructural effects can effectively affect the magnetoelectric response.

3.3. Material properties under tailored interface induced stress. The magnetic phase showed no significant differences in microstructure between the composites prepared with NFOWC and NFO-MA. Therefore, similar effective piezomagnetic coefficients are expected in both cases. Indeed, very similar magnetization hysteresis curves were obtained in both composites (see Figure S3a of the Supporting Information), to which the effective piezomagnetic coefficient 
is related as $q \alpha \partial M^{2} / \partial H .^{27}$ The latter magnitude is given as a function of the applied $d c$ magnetic field in Figure S3b of the Supporting Information. Accordingly, the study of the local functional properties was then focused on the piezoelectric component of the composites.

Local piezoelectric response under high interface induced stress. Let's first analyze the BSPT/NFO-MA composite, in which non-negligible residual stress within the piezoelectric layer is accompanied by very fine grained microstructure and distinct microstructural gradients. Unlike composites sintered by hot-pressing, ${ }^{28}$ grains at the interfaces of these SPS processed composite are piezoelectrically active, as the PFM images of Figure 3a,b indicate (see also Figure S4 of the Supporting Information for both out-of-plane and in-plane images). Distinctive ferroelectric domains can be seen within the grains. Besides, the local piezoelectric loops of grains next to the interface confirm the ferroelectric character of this region (Figure 3c).

A major feature in these local hysteresis loops is the lower coercive field values and larger piezoresponse obtained for grains next to the interface than for grains located far from it. This observation may be the consequence of the observed grain coarsening at the interfaces, for strong grain size effects have been described in the piezoelectric response of ferroelectrics, ${ }^{40}$ but it may also be related to differences in composition from the interface within the piezoelectric material, for a slight deviation along the phase diagram has a strong effect on properties. ${ }^{37}$ 
a)

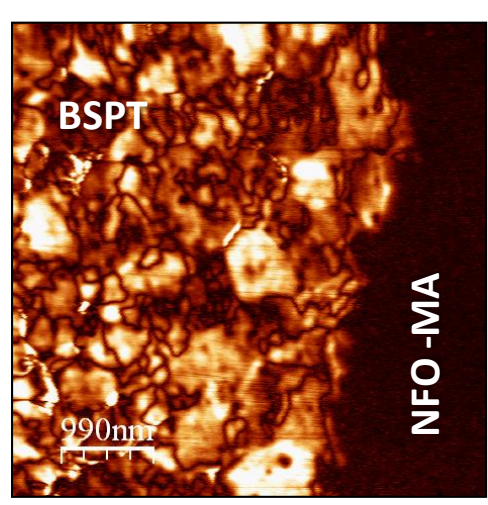

b)

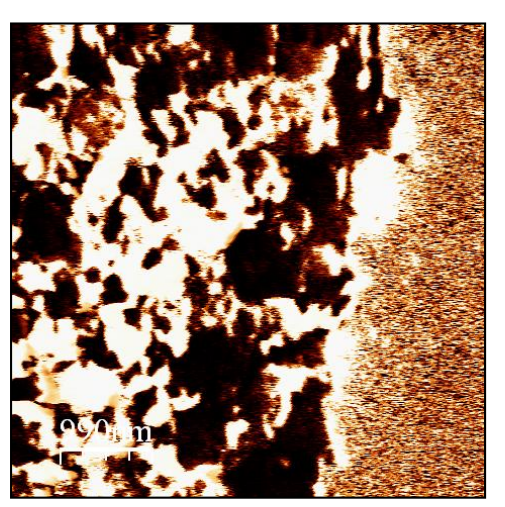

c)

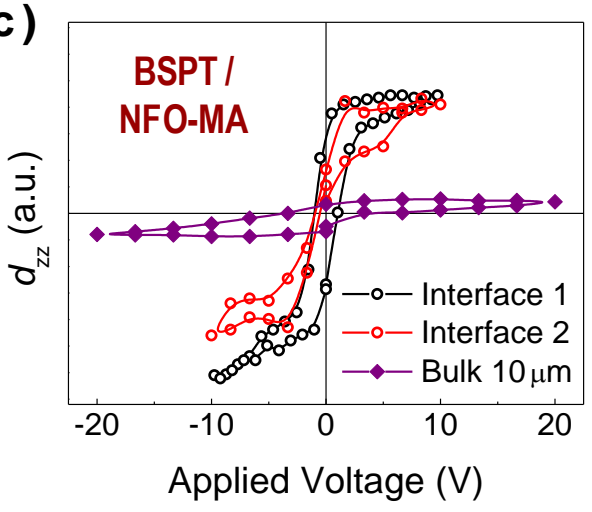

\section{BSPT / NFO-MA}

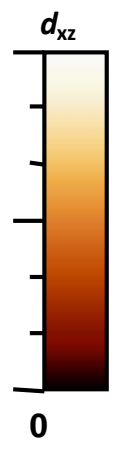

d)
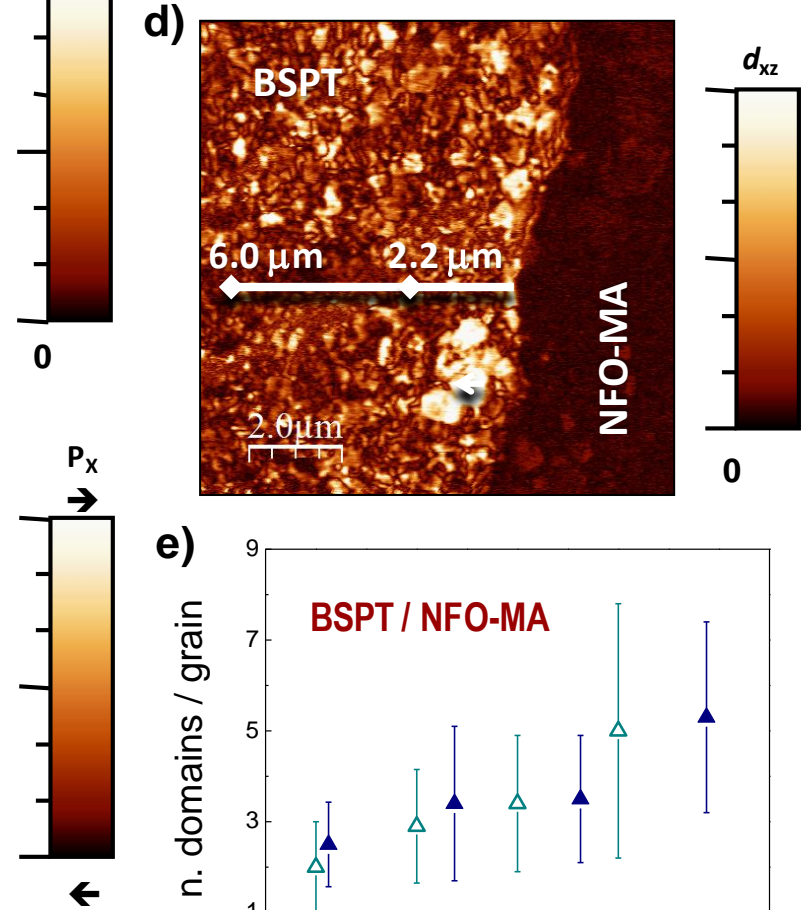

e)

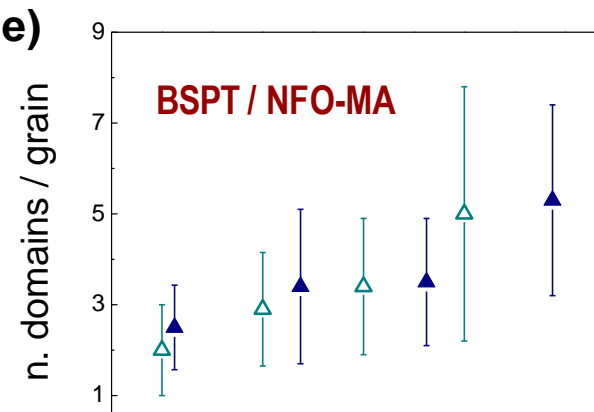

^ $0.0-2.2 \mu \mathrm{m}$ from Interface

f)

$\Delta 2.2-6.0 \mu \mathrm{m}$ from Interface

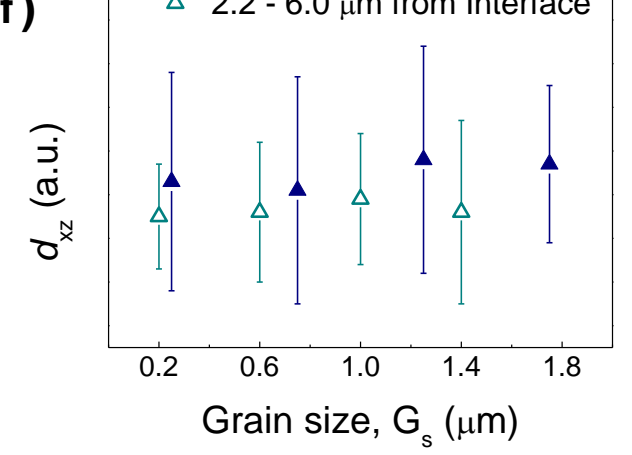

Figure 3. In-plane (a) amplitude and (b) phase PFM images at the interface of the BSPT/NFOMA three-layer composite, and (c) representative local in-field piezoelectric loops for different grains close to the interface (open symbols) and for a grain located at $10 \mu \mathrm{m}$ from the interface (labeled as Bulk). (d) Typical in-plane amplitude PFM image used for the quantitative analysis, along with the grain size dependences for each subset of grains of (e) the number of domains per grain and (f) the maximum piezoelectric coefficient $d_{\mathrm{xz}}$. 
The question is thus whether there is any difference between the piezoelectric activity of the grains next to the interface and the rest of the piezoelectric material beyond grain size effects. The challenge is the separation between differences due to grain size effects (already described for this composition) $)^{40}$ and those due to other interfacial effects. This was addressed by comparing data provided by the quantitative analysis of PFM images between two subsets of grains: (i) those situated below the first two microns of distance from the interface, that is the region where grain coarsening is observed, and (ii) those located between 2 and $6 \mu \mathrm{m}$ from the interface (Figure 3d). A statistically reliable number of measured grains was achieved for both regions, defining the boundary at $2.2 \mu \mathrm{m}$ for this composite. More details of these measurements can be found in Figure S5 of the Supporting Information.

As expected, the number of domains within each grain increases with the grain size, irrespective of their position with respect to the interface (Figure 3e). No significant differences were then found between the number of domains in the region close to the interface and the rest of the piezoelectric layer. Like the previous parameter, the average maximum in-plane piezoelectric coefficient, $d_{\mathrm{xz}}$, showed no significant differences between the two selected regions (Figure 3f) for a similar grain size. Actually, $d_{\mathrm{xz}}$ values are even slightly larger for grains in the region next to the interface. This allows chemical effects at the interfaces on the properties to be disregarded, for a slight deviation in composition out of the MPB of grains in the region next to the interface must have a detrimental effect on their piezoelectric response. ${ }^{37}$

Furthermore, little dependence of the $d_{\mathrm{xz}}$ coefficient with the grain size was obtained in both regions, in spite of a distinctive increase of the number of domains (Figure 3e,f). Single crystal properties, such as spontaneous polarization and piezoelectric coefficients, of ferroelectric 
perovskite oxides do not significantly vary in the submicron range, unlike domain configurations that continuously evolve with size decreases. ${ }^{40}$ Domain dynamics then determine polarization switching and retention, and thus, ceramic poling that becomes increasingly difficult with the microstructure refinement. This is most probably responsible of the lower piezoresponse of grains located far from the interface (Figure 3c). Residual tensile stresses within the layers can also play a role by further limiting poling.

Local piezoelectric response under minimized interface induced stress. A similar analysis was done with the BSPT/NFO-WC composite, in which tailored microstructure and low residual stress levels were achieved. Submicron sized grains at the interfaces were also piezoelectrically active and distinctive ferroelectric domains can be seen within the grains, as the PFM images of Figure 4a,b indicate (see also Figure S6 of the Supporting Information for both out-of-plane and in-plane PFM images). In this case, local piezoelectric loops were very similar for grains close to the interface and for those located far from it (Figure 4c), unlike the case of the BSPT/NFO-MA composite. PFM also revealed additional differences between the two composites. Ferroelectric domain configurations evolved differently with the distance from the interface (Figure S7 of the Supporting Information). In fact, this evolution reflects the variations of the grain size with distance: at $10 \mu \mathrm{m}$ from the interface, the larger size of the grains of BSPT/NFO-WC results in more complex ferroelectric domain configurations within the grains than those of BSPT/NFOMA, which only shows irregular walls corresponding to inversion domains. 
a)

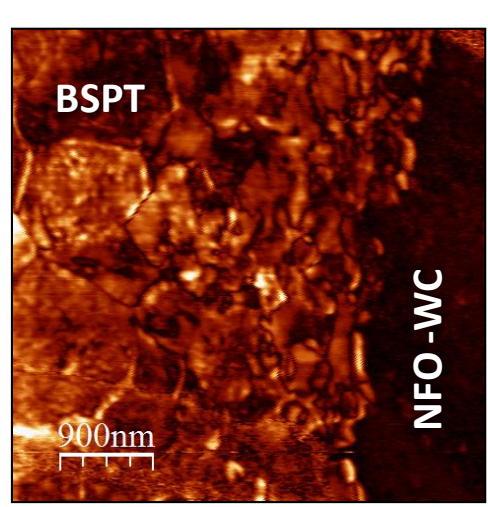

b)

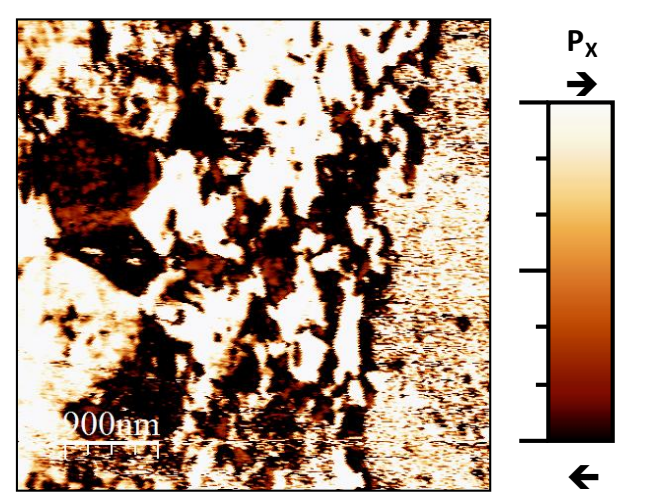

c)

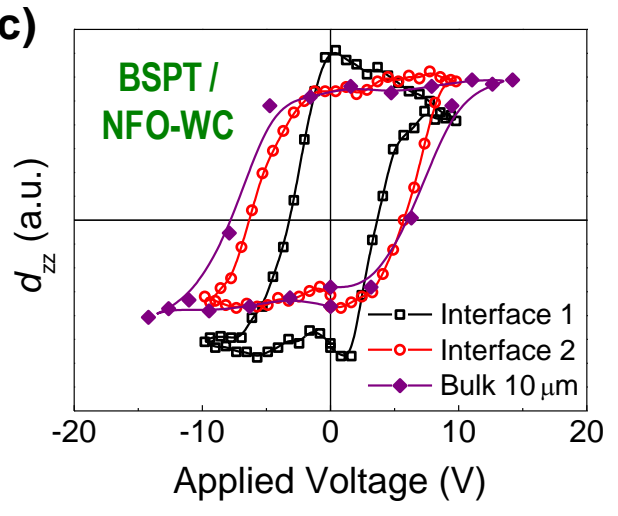

BSPT / NFO-WC

d)

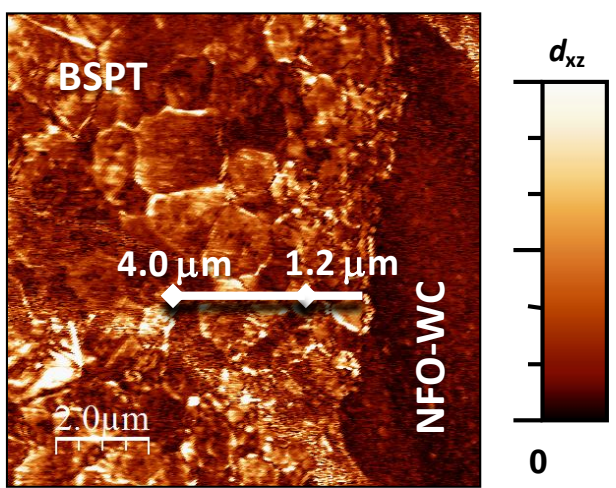

e)

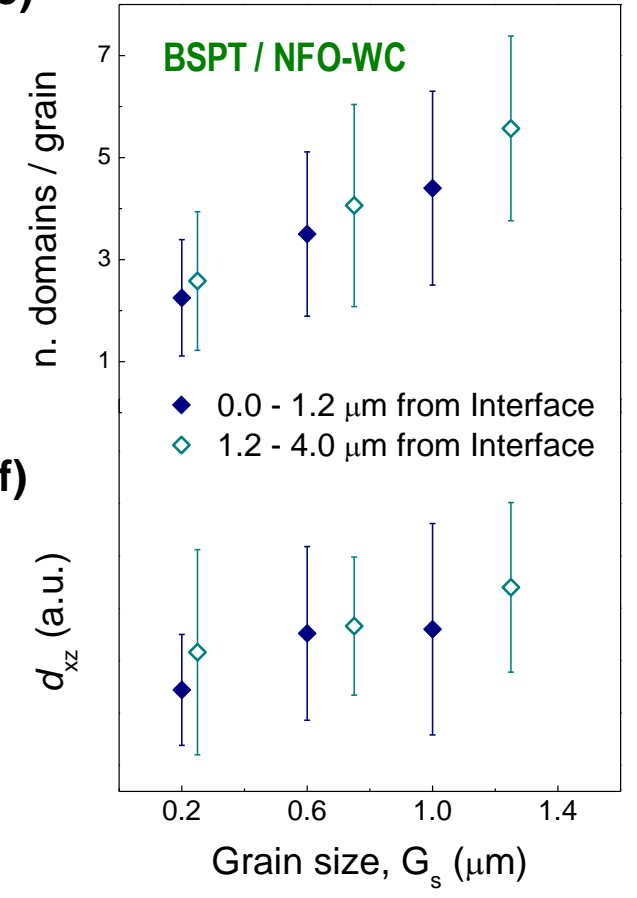

Figure 4. In-plane (a) amplitude and (b) phase PFM images at the interface of the BSPT/NFOWC three-layer composite, and (c) representative local in-field piezoelectric loops for different grains close to the interface (open symbols) and for a grain located at $10 \mu \mathrm{m}$ from the interface (labeled as Bulk). (d) Typical in-plane amplitude PFM image used for the quantitative analysis, along with the grain size dependences for each subset of grains of (e) the number of domains per grain and (f) the maximum piezoelectric coefficient $d_{x z}$. 
When comparing the data provided by the quantitative analysis of PFM images involving two subsets of grains between the composites processed from the two $\mathrm{NiFe}_{2} \mathrm{O}_{4}$ sources (Figures 3d-f and $4 \mathrm{~d}-\mathrm{f}$ ), different grain size dependences existed, so that the number of domains increased faster with size in the case of the BSPT/NFO-WC composite than in the case of the BSPT/NFOMA one (see also Figures S5 and S8 of the Supporting Information). This could be an effect of the presence of a stress field across the piezoelectric layer in the latter case that might hamper the formation of ferroelastic domains. On the contrary, no effects of possible highly localized stress fields next to the interface can be inferred in the case of the BSPT/NFO-WC composite. Like the number of domains, $d_{\mathrm{xz}}$ values showed no significant differences between the two selected regions for the latter composite, while an increase of the grain size always resulted in an increase of the piezoelectric response. This confirms that localized residual stress fields next to the interface play no role in this material.

3.4. Final considerations. Overall, the analysis carried out clearly indicates that functional interfaces were obtained with any of the two different $\mathrm{NiFe}_{2} \mathrm{O}_{4}$ sources. Functionality was further corroborated by local poling studies, as it is illustrated in Figure 5 for the BSPT/NFO-WC composite. Experiment consisted in the application of an electric field between the tip and the composite sample $(+20 \mathrm{~V})$ across a region of $10 \times 7.5 \mu^{2}$ area next to interface, followed by the application of an opposite field of the same magnitude on a smaller $5 \times 5 \mu \mathrm{m}^{2}$ area within it (Figure 5b). This resulted in an almost homogeneous poling of the in-plane polarization components, which is stable with time (Figure 5c). It must be pointed out that in this configuration the conductive $\mathrm{NiFe}_{2} \mathrm{O}_{4}$ serves as an electrode that allows the application of an inplane electric field. The subsequent application of a bias magnetic field on the composite (1000 Oe) only produced slight changes in the orientation of the polarization (Figure 5d). This is a 
typical maximum bias magnetic field applied during the magnetoelectric characterization of the composites, which is well above those for maximum response. Therefore, the experiment demonstrates the stability of the polarization at interfaces under operation conditions of a hypothetical magnetoelectric device.

a)

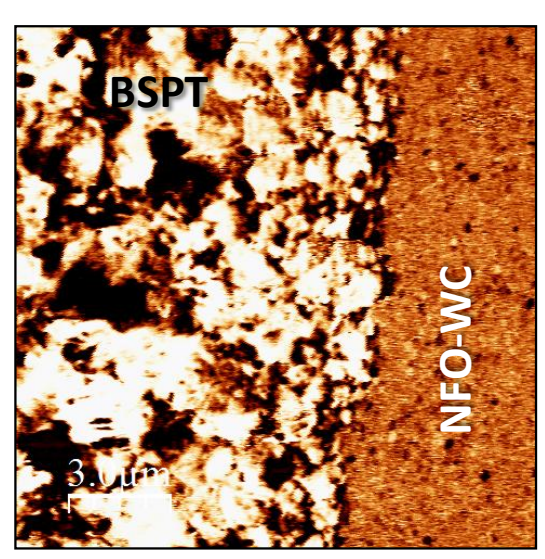

c)

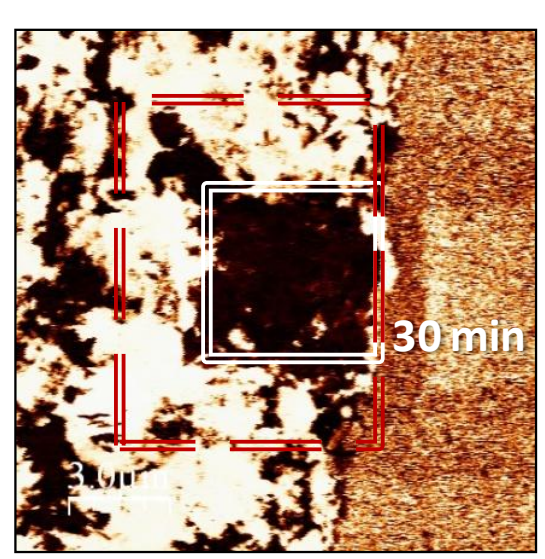

b)

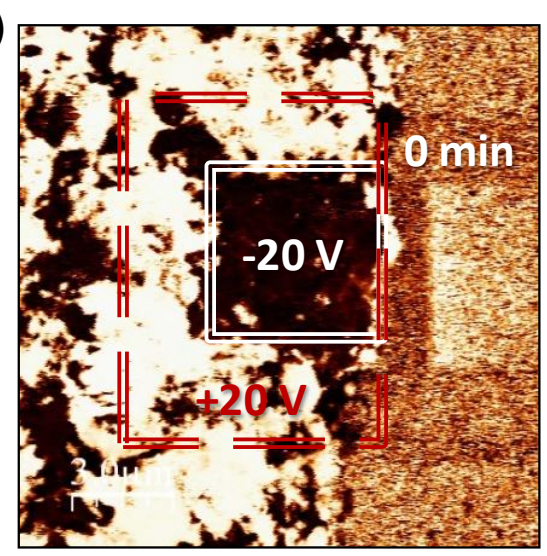

d)

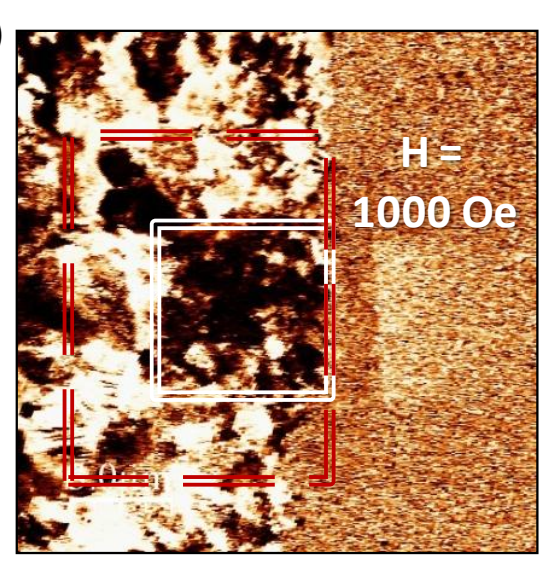

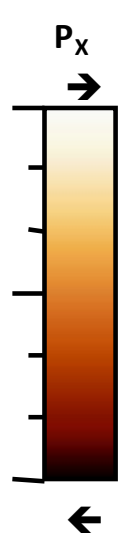

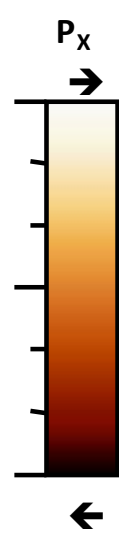

Figure 5. In-plane phase PFM images of the interface of the BSPT/NFO-WC three-layer composite. (a) before poling, (b) after poling first with $+20 \mathrm{~V}$ in the region delimited by the red line $\left(10 \times 7.5 \mu \mathrm{m}^{2}\right.$ area $)$, and then with $-20 \mathrm{~V}$ in the region delimited by the white line $\left(5 \times 5 \mu \mathrm{m}^{2}\right.$ area), (c) 30 min after poling, (d) after the application of a magnetic field $\mathrm{H}=1000$ Oe. 
Once both interfaces have been shown functional, differences in the magnetoelectric response must come from the distinct interface-stress induced microstructural effects in the multilayers. Indeed, magnetoelectric coefficients were significantly higher for the multilayer prepared with NFO-WC powder than for the one processed with NFO-MA (see Figure S9 of the Supporting Information). A transverse voltage coefficient $\alpha_{31}$ above $100 \mathrm{mV} \mathrm{cm}^{-1} \mathrm{Oe}^{-1}$ was achieved for the former material, while a value of about $50 \mathrm{mV} \mathrm{cm}^{-1} \mathrm{Oe}^{-1}$ was attained for the latter case. Results here reported indicate that this difference comes from a combined effect of the final ceramic microstructure and residual stress level: a larger grain size and lower residual stress resulted when the NFO-WC powder was used with a direct effect in the magnetoelectric response. Note that the two parameters are not independent and are determined by the sintering mismatch, so that response was tailored by selection of the $\mathrm{NiFe}_{2} \mathrm{O}_{4}$ source.

\section{SUMMARY AND CONCLUSIONS}

The characteristics of interfaces in high-quality multilayer ceramic magnetoelectric composites of $0.36 \mathrm{BiScO}_{3}-0.64 \mathrm{PbTiO}_{3} / \mathrm{NiFe}_{2} \mathrm{O}_{4}$, prepared by SPS of nanocrystalline powders, have been analyzed by several high-spatial resolution techniques, and information on their microstructure, stress and local functional properties has been extracted. It is shown that tailoring of the stresses developed during cosintering was possible through the choice of the source for the magnetic powder (via wet chemistry or mechanochemical activation). This is the key to the optimization of the ceramic microstructure and residual stress level, while obtaining functional interfaces. As a result, an enhanced magnetoelectric response of the multilayer was obtained when the residual tensile stress of the piezoelectric component at the interfaces is diminished thanks to its combination with magnetic layers with similar densification rate during sintering (that is, when $\mathrm{NiFe}_{2} \mathrm{O}_{4}$ is obtained by wet chemistry). Therefore, it can be concluded that the control of the 
sintering mismatch during cosintering of the components of the multilayers allows tailoring the microstructure and residual stresses of the interfaces for optimum magnetoelectric responses.

\section{ASSOCIATED CONTENT}

\section{Supporting Information}

Figure S1. Typical profiles out of plane and in plane PFM amplitude images; Figure S2. Raman spectra for coarse grained and nano-grained $0.36 \mathrm{BiScO}_{3}-0.64 \mathrm{PbTiO}_{3}$ ceramics; Figure $\mathrm{S} 3$. Magnetization loops as a function of magnetic field; Figure S4. Out of plane and in plane amplitude and phase PFM images of the BSPT/NFO-MA composite; Figure S5. Grain size and $d_{\mathrm{xz}}$ values measured from in-plane PFM images of the BSPT/NFO-MA composite; Figure S6. Out of plane and in plane amplitude and phase PFM images of the BSPT/NFO-WC composite; Figure S7. Topography and in plane PFM amplitude images within the piezoelectric layer of both composites; Figure S8. Grain size and $d_{\mathrm{xz}}$ values measured from in-plane PFM images of the BSPT/NFO-WC composite; Figure S9. Magnetoelectric voltage coefficient as a function of magnetic field for both multilayer composites.

\section{AUTHOR INFORMATION}

\section{Corresponding Author}

*E-mail: hamorin@icmm.csic.es (H.A.).

\section{ORCID}

Harvey Amorín: 0000-0001-9915-1631

\section{Present Addresses}


${ }^{*}$ Interdisciplinary Nanoscience Center, 8000 Aarhus, Denmark

${ }^{\S}$ Universidad Carlos III de Madrid, Avda. de la Universidad 30, 28911 Leganés, Spain

${ }^{\perp}$ Department of Physics, Federal University of Amazonas, Manaus, AM, Brazil

\# Institute for Welding and Quality, Av. Prof. Dr. Cavaco Silva 33, 2740-120, Oeiras, Portugal

\section{Author Contributions}

H.A., R.C., E.V. and A.C. carried out the synthesis and SPS experiments. J.R., I.S. and N.S. carried out the PFM characterization and analysis. Y.R. and J.P. carried out the micro-RAMAN measurements. P.R. and M.A. carried out the magnetoelectric characterization. M.A., J.R. and H.A. wrote the draft of the manuscript with input from all authors. H.A. and A.C. have coordinated the entire activity. All authors have given approval to the final version.

\section{Funding Sources}

Funded by Spanish MINECO through the MAT2014-58816-R project.

\section{Notes}

The authors declare no competing financial interest.

\section{ACKNOWLEDGMENT}

Authors are grateful to Prof. R. Moreno (ICV-CSIC, Madrid) for support in the tape-casting experiments, and to Dr. M. Dollé (CEMES-CNRS/PNF2, Toulouse) for support in the SPS experiments. Local poling PFM experiments were carried out by Ms. C. Díez. Technical supports by Ms. I. Martínez and Ms. M. M. Antón are also acknowledged.

\section{ABBREVIATIONS}


SPS, spark plasma sintering

PFM, piezoresponse force microscope

NFO-MA, $\mathrm{NiFe}_{2} \mathrm{O}_{4}$ powder prepared by mechanochemical activation

$\mathrm{NFO}-\mathrm{WC}, \mathrm{NiFe}_{2} \mathrm{O}_{4}$ powder prepared wet chemistry route

BSPT, 0.36BiScO $3-0.64 \mathrm{PbTiO}_{3}$

\section{REFERENCES}

(1) Fiebig, M. Revival of the Magnetoelectric Effect. J. Phys. D: Appl. Phys. 2005, 38, R123$\mathrm{R} 152$.

(2) Liu, M.; Obi, O.; Lou, J.; Chen, Y.; Cai, Z.; Stoute, S.; Espano, M.; Lew, M.; Situ, X.;

Ziemer, K. S.; Harris, V. G.; Sun, N. X. Giant Electric Field Tuning of Magnetic Properties in Multiferroic Ferrite/Ferroelectric Heterostructures. Adv. Funct. Mater. 2009, 19, 1826-1831.

(3) Sun, Y.; Ba, Y.; Chen, A.; He, W.; Wang, W.; Zheng, X.; Zou, L.; Zhang, Y.; Yang, Q.;

Yan, L.; Feng, C.; Zhang, Q.; Cai, J.; Wu, W.; Liu, M.; Gu, L.; Cheng, Z.; Nan, C. W.; Qiu, Z.;

Wu, Y.; Li, J.; Zhao, Y. Electric-Field Modulation of Interface Magnetic Anisotropy and Spin Reorientation Transition in $(\mathrm{Co} / \mathrm{Pt})_{3} / \mathrm{PMN}-\mathrm{PT}$ Heterostructure. ACS Appl. Mater. Interfaces 2017, 9, 10855-10864.

(4) Paluszek, M.; Avirovik, D.; Zhou, Y.; Kundu, S.; Chopra, A.; Montague, R.; Priya, S. Magnetoelectric Composites for Medical Application. In Composite Magnetoelectrics; Srinivasan, G., Priya, S., Sun, N. X., Eds.; Woodhead Publishing: Cambridge, UK, 2015; pp 297-327.

(5) Scott, J. F. Applications of Magnetoelectrics. J. Mater. Chem. 2012, 22, 4567-4574. 
(6) Wang, Y.; Li, J.; Viehland, D. Magnetoelectrics for Magnetic Sensor Applications: Status, Challenges and Perspectives. Mater. Today 2014, 17, 269-275.

(7) Mandal, P.; Pitcher, M. J.; Alaria, J.; Niu, H.; Borisov, P.; Stamenov, P.; Claridge, J. B.; Rosseinsky, M. J. Designing Switchable Polarization and Magnetization at Room Temperature in an Oxide. Nature 2015, 525, 363-366.

(8) Fernandez-Posada, C. M.; Castro, A.; Kiat, J. M.; Porcher, F.; Peña, O.; Algueró, M.; Amorín, H. A Novel Perovskite Oxide Chemically Designed to Show Multiferroic Phase Boundary with Room-Temperature Magnetoelectricity. Nat. Commun. 2016, 7, 12772.

(9) Heron, J. T.; Bosse, J. L.; He, Q.; Gao, Y.; Trassin, M.; Ye, L.; Clarkson, J. D.; Wang, C.; Liu, J.; Salahuddin, S.; Ralph, D. C.; Schlom, D. G.; Íñiguez, J.; Huey, B. D.; Ramesh, R. Deterministic Switching of Ferromagnetism at Room Temperature using an Electric Field. Nature 2014, 516, 370-373.

(10) Bibes M.; Barthelemy, A. Multiferroics: Towards a Magnetoelectric Memory. Nat. Mater. 2008, 7, 425-426.

(11) Tsymbal, E. Y.; Gruverman, A.; Garcia, V.; Bibes, M.; Barthelemy, A. Ferroelectric and Multiferroic Tunnel Junctions. MRS Bull. 2012, 37, 138-143.

(12) Zheng, H.; Wang, J.; Lofland, S. E.; Ma, Z.; Mohaddes-Ardabili, L.; Zhao, T.; SalamancaRiba, L.; Shinde, S. R.; Ogale, S. B.; Bai, F.; Viehland, D.; Jia, Y.; Schlom, D. G.; Wuttig, M.; Roytburd, A.; Ramesh, R. Multiferroic $\mathrm{BaTiO}_{3}-\mathrm{CoFe}_{2} \mathrm{O}_{4}$ Nanostructures. Science 2004, 303, 661-663.

(13) Algueró, M.; Ricote, J.; Torres, M.; Amorín, H.; Alberca, A.; Iglesias-Freire, O.; Nemes, N.; Holgado, S.; Cervera, M.; Piqueras, J.; Asenjo, A.; García-Hernández, M. Thin Film 
Multiferroic Nanocomposites by Ion Implantation. ACS Appl. Mater. Interfaces 2014, 6, 19091915.

(14) Vaz, C. A. F.; Hoffman, J.; Ahn, C. H.; Ramesh, R. Magnetoelectric Coupling Effects in Multiferroic Complex Oxide Composite Structures. Adv. Mater. 2010, 22, 2900-2918.

(15) Hu, J. M.; Chen, L. Q.; Nan, C. W. Multiferroic Heterostructures Integrating Ferroelectric and Magnetic Materials. Adv. Mater. 2016, 28, 15-39.

(16) Nan, C. W.; Bichurin, M. I; Dong, S.; Viehland, D.; Srinivasan, G. Multiferroic Magnetoelectric Composites: Historical Perspective, Status, and Future Directions. J. Appl. Phys. 2008, 103, 031101.

(17) Srinivasan, G. Magnetoelectric Composites. Annu. Rev. Mater. Res. 2010, 40, 153-178.

(18) Ma, J.; Hu, J.; Li, Z.; Nan, C. W. Recent Progress in Multiferroic Magnetoelectric Composites: from Bulk to Thin Films. Adv. Mater. 2011, 23, 1062-1087.

(19) Jin, J.; Zhao, F.; Han, K.; Haque, M. A.; Dong, L.; Wang, Q. Multiferroic Polymer Laminate Composites Exhibiting High Magnetoelectric Response Induced by HydrogenBonding Interactions. Adv. Funct. Mater. 2014, 24, 1067-1073.

(20) Dong, S.; Zhai, J.; Li, J.; Viehland, D. Near-Ideal Magnetoelectricity in High Permeability Magnetostrictive/Pizofiber Laminates with (2-1) Connectivity. Appl. Phys. Lett. 2006, 89, 252904.

(21) Silva, M.; Reis, S.; Lehmann, C. S.; Martins, P.; Lanceros-Mendez, S.; Lasheras, A.; Gutiérrez, J.; Barandiarán, J. M. Optimization of the Magnetoelectric Response of Poly(vinylidenefluoride)/epoxy/vitrovac Laminates. ACS Appl. Mater. Interfaces 2013, 5, 10912-10919. 
(22) Park C. S.; Priya, S. Cofired Magnetoelectric Laminate Composites. J. Am. Ceram. Soc.

2011, 94, 1087-1095.

(23) Zhou, Y.; Yan, Y.; Priya, S. Co-Fired Magnetoelectric Transformer. Appl. Phys. Lett. 2014, 104, 232906.

(24) Bush, A. A.; Shkuratov, V. Y.; Chernykh, I. A.; Fetisov, Y. K. Lead Zirconate TitanateNickel Zink Ferrite Thick-Film Composites: Obtaining by the Screen Printing Technique and Magnetoelectric Properties. Tech. Phys. 2010, 55, 387-394.

(25) Srinivasan, G.; Rasmussen, E. T.; Gallegos, J.; Srinivasan, R. Magnetoelectric Bilayer and Multilayer Structures of Magnetostrictive and Piezoelectric Oxides. Phys. Rev. B 2001, 64, 214408.

(26) Islam, R. A.; Ni, Y.; Khachaturyan A. G.; Priya, S. Giant Magnetoelectric Effect in Sintered Multilayered Composite Structures. J. Appl. Phys. 2008, 104, 044103.

(27) Amorín, H.; Algueró, M.; Del Campo, R.; Vila, E.; Ramos, P.; Dolle, M.; RomagueraBarcelay, Y.; Pérez de la Cruz, J.; Castro, A. High-Sensitivity Piezoelectric Perovskite for Magnetoelectric Composites. Sci. Technol. Adv. Mater. 2015, 16, 016001.

(28) Amorín, H.; Hungría, T.; Landa-Cánovas, A. R.; Torres, M.; Dollé, M.; Algueró, M.; Castro, A. Nanopowders of Ferroic Oxides for Magnetoelectric Composites. J. Nanopart. Res. 2011, 13, 4189-41200.

(29) Hungría, T.; Amorín, H.; Algueró, M.; Castro, A. Nanostructured Ceramics of BiScO $3^{-}$ $\mathrm{PbTiO}_{3}$ with Tailored Grain Size by Spark Plasma Sintering. Scripta Mater. 2011, 64, 97-100.

(30) Deluca, M.; Gajovic, A. Raman Spectroscopy of Nanostructured Ferroelectric Materials. In Nanoscale Ferroelectrics and Multiferroics: Key Processing and Characterization Issues, and 
Nanoscale Effects; Algueró, M., Gregg, J. M., Mitoseriu, L., Eds.; John Wiley \& Sons, Ltd, Chichester, UK, 2016; pp 325-374.

(31) Mota, D.; Chandra, G. H.; Ventura, J.; Guedes, A.; Pérez de la Cruz, J. Influence of Process Parameters on the RF Sputtered GaP Thin Films. J. Mater. Sci. Technol. 2013, 29, 821829.

(32) Alexe, M.; Gruverman, A. Nanoscale Characterization of Ferroelectric Materials:

Scanning Probe Microscopy Approach. Springer-Verlag, Berlin, Germany, 2004.

(33) Horcas, I.; Fernández, R.; Gómez-Rodríguez, J. M.; Colchero, J.; Gómez-Herrero, J.;

Baro, A. M. WSXM: A Software for Scanning Probe Microscopy and a Tool for Nanotechnology. Rev. Sci. Instrum. 2007, 78, 013705.

(34) Green, D. J.; Guillon O.; Rödel, J. Constrained Sintering: A Delicate Balance of Scales. J. Eur. Ceram. Soc. 2008, 28, 1451-1466.

(35) Cai, P. Z.; Green, D. J.; Messing, G. L. Constrained Densification of Alumina/Zirconia Hybrid Laminates, I: Experimental Observations of Processing Defects. J. Am. Ceram. Soc. 1997, 80, 1929-1939.

(36) Amorín, H.; Jiménez, R.; Deluca, M.; Ricote, J.; Hungría, T.; Castro, A.; Algueró, M. Nanostructuring Effects in Piezoelectric $\mathrm{BiScO}_{3}-\mathrm{PbTiO}_{3}$ Ceramics. J. Am. Ceram. Soc. 2014, 97, 2802-2809.

(37) Eitel, R. E.; Zhang, J. S.; Shrout, T. R.; Randall, C. A.; Levin, I. Phase Diagram of the Perovskite System (1-x) $\mathrm{BiScO}_{3}-x \mathrm{PbTiO}_{3}$. J. Appl. Phys. 2004, 96, 2828-2831. 
(38) Carreaud, J.; Kiat, J. M.; Dkhil, B.; Algueró, M.; Ricote, J.; Jiménez, R.; Holc, J.; Kosec, M. Monoclinic Morphotropic Phase and Grain Size-Induced Polarization Rotation in $\mathrm{Pb}\left(\mathrm{Mg}_{1 / 3} \mathrm{Nb}_{2 / 3}\right) \mathrm{O}_{3}-\mathrm{PbTiO}_{3}$. Appl. Phys. Lett. 2006, 89, 252906.

(39) Wesselinowa J. M.; Kovachev St. Hardening and Softening of Soft Phonon Modes in Ferroelectric Thin Films. Phys. Rev. B 2007, 75, 045411.

(40) Salazar, N.; Algueró, M.; Amorín, H.; Castro, A.; Gil, A.; Ricote, R. Local Characterization of Nanostructured High Sensitivity Piezoelectric $\mathrm{BiScO}_{3}-\mathrm{PbTiO}_{3}$ Ceramics by Piezoresponse Force Microscopy. J. Appl. Phys. 2014, 116, 124108. 
TABLE OF CONTENTS GRAPHIC

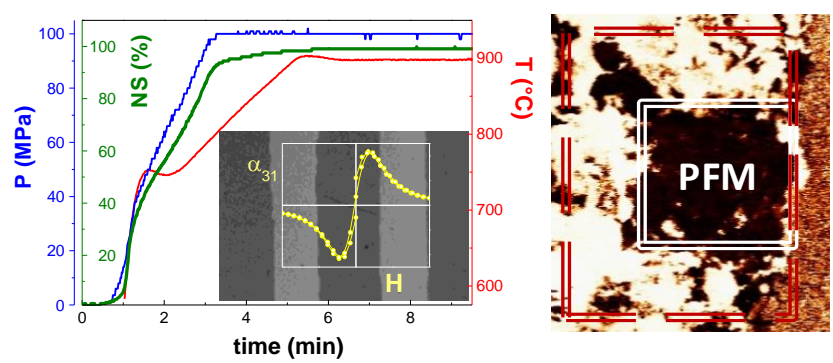

